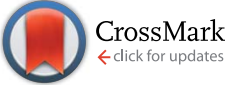

Cite this: RSC Adv., 2016, 6, 61650

\title{
Ammonia capture from the gas phase by encapsulated ionic liquids (ENILs) $\uparrow$
}

\author{
Jesus Lemus, Jorge Bedia, Cristian Moya, Noelia Alonso-Morales, Miguel A. Gilarranz, \\ Jose Palomar* and Juan J. Rodriguez
}

Encapsulated ionic liquids (ENILs) based on carbonaceous submicrocapsules were designed, synthesized and applied to the sorption of $\mathrm{NH}_{3}$ from gas streams. The ENILs were prepared using three different task-specific ILs with adequate properties for $\mathrm{NH}_{3}$ capture: 1-(2-hydroxyethyl)-3-methylimidazolium tetrafluoroborate $\left(\mathrm{EtOHmimBF}_{4}\right)$, choline bis(trifluoromethylsulfonyl)imide (CholineNTf $)$ and tris(2hydroxyethyl)methylammonium methylsulfate $\left[(\mathrm{EtOH})_{3} \mathrm{MeNMeSO}_{4}\right]$. The ENILs synthesized were analyzed by different techniques to assess their morphology, chemical composition, porous structure and thermal stability. The capture of $\mathrm{NH}_{3}$ was tested in fixed-bed experiments under atmospheric pressure. The influence of the type and load of $\mathrm{IL}$, temperature $\left(30,45\right.$ and $60{ }^{\circ} \mathrm{C}$ ) and $\mathrm{NH}_{3}$ inlet concentration was analyzed. Desorption of $\mathrm{NH}_{3}$ from the exhausted ENILs was also studied at atmospheric pressure and temperatures in the range of 150 to $200{ }^{\circ} \mathrm{C}$. The ENILs prepared with taskspecific ILs were found to be suitable for $\mathrm{NH}_{3}$ capture in the fixed-bed operation. These systems can be a promising alternative to conventional absorption or adsorption due to: (i) high sorption capacity controlled by IL selection, (ii) remarkable mass transfer rate, (iii) low sensitiveness to high temperatures of the gas stream, (iv) fast and complete regeneration of the exhausted ENIL at mild conditions; and (v) recovery of $\mathrm{NH}_{3}$.

Received 5th May 2016

Accepted 21st June 2016

DOI: 10.1039/c6ra11685j

www.rsc.org/advances
$\mathrm{NH}_{3}$ absorbents in industrial processes of interest, such as absorption refrigeration cycles. ${ }^{24-26}$ However, the transport properties of ILs represent still a main limitation for practical applications; ${ }^{27}$ in particular, ILs generally exhibit much higher viscosity than conventional organic solvents. ${ }^{28,29}$

In this sense, novel materials named Supported Ionic Liquid Phase (SILP), ${ }^{30-35}$ consisting of the immobilization of ILs on a solid support, have been proposed as a technical solution to overcome the mass transfer limitations of ILs in gas-liquid separation processes. ${ }^{36-40}$ SILP materials are commonly prepared by spreading a thin layer of IL onto the surface of a solid support, mostly consisting of materials with high specific surface area, ${ }^{33}$ like $\mathrm{TiO}_{2},{ }^{41} \mathrm{SiO}_{2}{ }^{42}$ or AC. ${ }^{39}$ It has been demonstrated that the IL immobilization on a porous support drastically increases the gas/liquid contact area, leading to much faster sorption rates than in the case of bulk IL. ${ }^{43,44}$ However, one of the main drawback for the application of SILP materials in gas separation processes is the limited amount of IL uploaded onto the support (generally lower than $20 \% \mathrm{w} / \mathrm{w},{ }^{45}$ reaching up to $50 \% \mathrm{w} / \mathrm{w}$ in some cases ${ }^{40,46}$ ), that limits their application in gas separation processes. In this context, the new concept of encapsulated ionic liquids (ENILs) has arisen as an interesting alternative. ${ }^{47-53}$ In a pioneer work, Deng et al. synthesized a highly dispersed IL material through the physical encapsulation of the IL in a silica-gel matrix through a sol-gel process, thus reaching IL contents from 8 to $53 \% \mathrm{w} / \mathrm{w}^{47}$
Sección de Ingeniería Quimica (Departamento de Quimica Física Aplicada), Universidad Autónoma de Madrid, 28049 Madrid, Spain. E-mail: pepe.palomar@ uam.es

$\dagger$ Electronic supplementary information (ESI) available. See DOI: 10.1039/c6ra11685j 
Nanocomposites of ILs confined in mesoporous silica gels were successfully applied to the selective adsorption of $\mathrm{CO}_{2} / \mathrm{N}_{2}$ streams. ${ }^{48}$ We recently presented ENIL materials ${ }^{53}$ consisting of hollow carbonaceous submicrocapsules $\left(\mathrm{C}_{\text {cap }}\right)$ that confine ILs. ${ }^{54-56}$ The synthesis of ENILs is favored by the high affinity found between ILs and AC. ${ }^{56-59}$ The novel material is characterized by a high amount of IL incorporated (70-85\%, w) and capsule particle size ranging from 450 to $800 \mathrm{~nm}$. This ENIL material implies a shift from a continuous to a discrete IL phase with submicron size units, thus drastically increasing the specific contact area with respect to the neat IL. ${ }^{53}$ Moreover, ENIL show the additional advantage of their high versatility, since they can be prepared at different loads (up to $80 \% \mathrm{w} / \mathrm{w}$ ) using ILs with optimized properties for a specific application. In a previous work, ${ }^{53}$ the capture of $\mathrm{NH}_{3}$ was preliminary tested at atmospheric pressure with ENILs prepared using the taskspecific IL 1-2(-hydroxyethyl)-3-methylimidazolium tetrafluoroborate (EtOHmimBF $)$, with a high $\mathrm{NH}_{3}$ absorption capacity. Efforts to develop new sorbents based on ILs and to apply them in the removal of $\mathrm{NH}_{3}$ from gas stream have also been recently reported by Kohler et $a .^{60}$ In their approach, a solution of metal complexes in IL was supported onto polymer-based spherical ACs, obtaining very high capacity by irreversible chemical absorption of $\mathrm{NH}_{3}$.

The objective of this work is to evaluate the potential application of ENILs for the purification of gas streams contaminated with $\mathrm{NH}_{3}$, with further recovery of this compound. The ENILs used have been designed to provide high $\mathrm{NH}_{3}$ physical sorption capacities, high mass transfer rates, thermal stability and favorable regeneration. Hollow carbon submicrospheres with a thick porous wall were synthesized by templating method in order to increase their mechanical strength. ${ }^{56}$ Then, the ENILs were prepared by introducing in the microcapsules different loads $(33-80 \% \mathrm{w} / \mathrm{w})$ of three selected task-specific ILs showing outstanding $\mathrm{NH}_{3}$ absorption capacity and relatively high $\mathrm{NH}_{3}$ diffusion coefficients: $:^{2,23}$ 1-2(-hydroxyethyl)3-methylimidazolium tetrafluoroborate $\left(\mathrm{EtOHmimBF}_{4}\right)$, choline bis(trifluoromethylsulfonyl)imide (CholineNTf ${ }_{2}$ ) and tris(2-hydroxyethyl)-methylammoniummethylsulfate $\left[(\mathrm{EtOH})_{3}\right.$ $\mathrm{MeNMeSO}_{4}$ ] (Table 1). The ENILs were characterized by several techniques, including scanning and transmission electron microscopy (SEM and TEM), elemental analysis (EA), $\mathrm{N}_{2}$ adsorption-desorption at $-196{ }^{\circ} \mathrm{C}$ and thermogravimetric analysis (TGA). They were compared to the corresponding benchmark materials namely the empty carbon submicrocapsules $\left(\mathrm{C}_{\text {cap }}\right)$ and the neat ILs. The fixed-bed sorption experiments were carried out in fixed bed at temperatures ranging from 30 to $60^{\circ} \mathrm{C}$ and inlet $\mathrm{NH}_{3}$ concentrations from 500 to $2000 \mathrm{ppmv}$. The influence of the chemical nature and the load of IL in the ENILs was analyzed at different operating conditions. The regeneration of the exhausted ENIL beds was assessed by desorption experiment performed under $\mathrm{N}_{2}$ flow at temperatures between 120 and $200{ }^{\circ} \mathrm{C}$.

\section{Materials and methods}

\subsection{Materials}

Phenol (99\%), paraformaldehyde (95-100\%), aluminum trichloride (95-100\%), ammonia (38\%), absolute ethanol, hydrofluoric acid (48\%) and sodium hydroxide was purchased from

Table 1 Ionic liquid structures and abbreviations

\begin{tabular}{lll}
\hline Structure & Abbreviation & Name \\
\hline & EtOHmimBF$_{4}$ & 1-(2-Hydroxyethyl)-3-methylimidazolium tetrafluoroborate
\end{tabular}<smiles>C[N+](C)(C)CCO</smiles>
Choline bis(trifluoromethylsulfonyl)imide
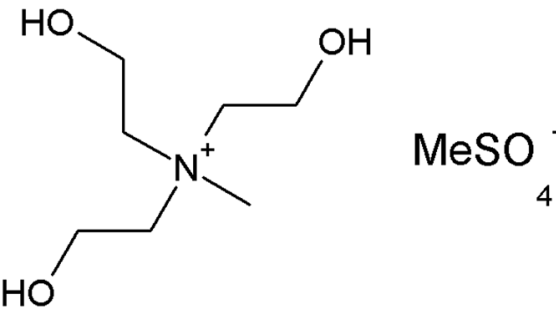
Panreac, and tetraethylorthosilicate (98\%) (TEOS) and octadecyltrimethoxysilane (90\%) (C18TMS) from Sigma-Aldrich. The ILs 1-(2-hydroxyethyl)-3-methylimidazolium tetrafluoroborate $\left(\mathrm{EtOHmimBF}_{4}\right)$, choline bis(trifluoromethylsulfonyl) imide (CholineNTf ${ }_{2}$ ) and tris(2-hydroxyethyl)-methylammonium methylsulfate $\left[(\mathrm{EtOH})_{3} \mathrm{MeNMeSO}_{4}\right]$ were supplied by Iolitec in the highest purity available (purity $>97-98 \%$ ). They were used as received.

To prevent hydration, acetone and ILs were kept in their original tightly closed bottles in a desiccator before use, and they were manipulated inside a glovebox under dry nitrogen atmosphere.

The sorption experiments were carried out using a commercial mixture of $\mathrm{N}_{2}$ and $\mathrm{NH}_{3}(2000 \mathrm{ppmv})$ and $\mathrm{N}_{2}$ (purity > 99.99\%) supplied by Praxair.

\subsection{Preparation of ENILs}

Carbon submicrocapsules $\left(\mathrm{C}_{\text {cap }}\right)$ with a thick wall were synthesized following the template method, as detailed in previous works, ${ }^{53,56}$ to achieve high mechanical resistance and porosity. The $\mathrm{C}_{\text {cap }}$ were filled by successive impregnation steps of $100 \mathrm{mg}$ of hollow carbon capsules with $1 \mathrm{~mL}$ of IL-acetone solution. ${ }^{46}$ The number of impregnation steps and the concentration of IL in the acetone solution were adjusted to obtain ENILs with different IL loadings. To ensure a homogeneous penetration of the IL solution into the pores, it was added dropwise over the $\mathrm{C}_{\text {cap }}$, followed by vacuum evacuation of acetone at $60^{\circ} \mathrm{C}$ and 10 mbar for $2 \mathrm{~h}$. The ENILs synthesized contained from 33 to $80 \%$ of IL (w, ENIL basis), i.e. IL/carbon mass ratios between 0.5 and $4\left(R_{0.5}-R_{4}\right)$. The amount of IL loaded was calculated as the difference between the weight of the final ENIL and the starting $\mathrm{C}_{\text {cap }}$. Those measurements were validated by the $\mathrm{N}$ content determined by elemental analysis (EA), as established in a previous work. ${ }^{46}$

All the ENILs prepared had the resemblance and texture of a powdered material. The ENILs were stored at $90{ }^{\circ} \mathrm{C}$ during 24 $\mathrm{h}$ prior to their use.

\subsection{Characterization of ENILs}

The morphology and microstructure of $\mathrm{C}_{\mathrm{cap}}$ and ENILs were studied by scanning and transmission electron microscopy (SEM and TEM). SEM micrographs were obtained using a Hitachi S-3000N model and TEM images in a Philips 420 microscope. Elemental analyses (EA) of $\mathrm{C}_{\text {cap }}$ and ENILs were carried out in a Perkin-Elmer analyzer (210 CHN model) to obtain C, H and $\mathrm{N}$ content. The porous structure was characterized by means of nitrogen adsorption-desorption isotherms at $-196^{\circ} \mathrm{C}$ using a Micromeritics apparatus (Tristar II 3020 model). The samples were previously outgassed at $150{ }^{\circ} \mathrm{C}$ and 70 mTorr for 6 $\mathrm{h}$. The BET equation was applied to determine the total surface area $\left(A_{\mathrm{BET}}\right)$, and the external or non-micropore area $\left(A_{\mathrm{s}}\right)$ was obtained using the $t$-method. The Dubinin-Radushkevich equation was applied for micropore volume estimation. The difference between the volume of $\mathrm{N}_{2}$ adsorbed (as liquid) at 0.95 relative pressure and the micropore volume was taken as the mesopore volume, and the DFT method was used to obtain the pore size distribution. ${ }^{61}$ Thermogravimetric analyses (TGA) of ILs and ENILs were conducted in a Mettler Toledo Instrument (TGA/SDTA851e model) under nitrogen atmosphere. A dynamic method was used within the temperature range from 50 to 600 ${ }^{\circ} \mathrm{C}$ at a heating rate of $10{ }^{\circ} \mathrm{C} \mathrm{min}^{-1}$ under a nitrogen flow of 50 $\mathrm{mL} \min ^{-1}$. The accuracy of temperature and mass measurements was $0.1{ }^{\circ} \mathrm{C}$ and $10^{-3} \mathrm{mg}$, respectively. Aluminum pans were used to hold an initial mass between 4 and $12 \mathrm{mg}$. The derivative curves (DTG) were also obtained to assess the temperature of IL decomposition in the ENILs.

\section{4. $\mathbf{N H}_{3}$ capture experiments}

The sorption of ammonia was performed in a fixed bed with the ENIL (50-250 mg) placed in a quartz column ( $4 \mathrm{~mm}$ of internal diameter and $4-5 \mathrm{~cm}$ of length). $\mathrm{N}_{2}-\mathrm{NH}_{3}$ mixtures (500-2000 ppmv $\mathrm{NH}_{3}$ ) were continuously passed at $20 \mathrm{~mL} \mathrm{~min}^{-1}$ flow rate. Different temperatures within the $30-60{ }^{\circ} \mathrm{C}$ range were tested and the operating pressure was $\sim 1 \mathrm{~atm} . \mathrm{NH}_{3}$ was analyzed at the exit of the column with a quadrupole mass analyzer (OmniStar/ThermoStar).

The $\mathrm{NH}_{3}$ uptake at saturation $\left(q_{\mathrm{s}}, \mathrm{mg} \mathrm{g}^{-1}\right)$ for $\mathrm{C}_{\text {cap }}$ and ENILs were calculated from the breakthrough curves as:

$$
q_{\mathrm{s}}=\frac{Q}{m} \int_{0}^{t_{\mathrm{s}}}\left(C_{\mathrm{o}}-C\right) \mathrm{d} t
$$

where $Q$ is the gas flow rate $\left(\mathrm{L} \mathrm{min}^{-1}\right) ; m$ is the mass of $\mathrm{C}_{\text {cap }}$ or ENIL in the column (g); $C$ and $C_{\mathrm{o}}$ represent the exit and the inlet $\mathrm{NH}_{3}$ concentration $\left(\mathrm{mg} \mathrm{L}^{-1}\right)$, respectively, and $t_{\mathrm{s}}$ corresponds to the time at which $C$ equals $C_{\mathrm{o}}$. The comparison of the capacity of the different ENILs was made in terms of per unit mass of ENIL $\left(q_{\mathrm{s}, \mathrm{ENIL}} ; \mathrm{mg}^{\mathrm{ENNIL}^{-1}}\right)$, unit mass of IL $\left(q_{\mathrm{s}, \mathrm{IL}} ; \mathrm{mg} \mathrm{g}_{\mathrm{IL}}{ }^{-1}\right)$ or unit volume of the packed bed $\left(q_{\mathrm{s}, \mathrm{v}} ; \mathrm{mg} \mathrm{cm}{ }^{-3}\right)$. The breakthrough time $\left(t_{\mathrm{b}}\right)$ was defined as the time at which the $C / C_{\mathrm{o}}$ ratio reached a value of 0.05 .

The length of the mass transfer zone $\left(h_{\mathrm{MTZ}}\right)$ was estimated from the breakthrough curves using the expression:

$$
h_{\mathrm{MTZ}}=\frac{\left(t_{0.95}-t_{0.05}\right)}{t_{0.95}} h
$$

where $h$ is the length of the entire sorbent bed in the column, $t_{0.95}$ and $t_{0.05}$ are the times at which the exit $\mathrm{NH}_{3}$ concentration reaches $95 \%$ and $5 \%$ of the inlet value, respectively.

Desorption experiments were performed after the saturation

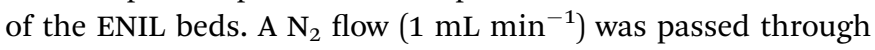
the exhausted bed at $200{ }^{\circ} \mathrm{C}$ during 30 minutes. In the case of $(\mathrm{EtOH})_{3} \mathrm{MeNMeSO}_{4}$, a regeneration temperature of $150{ }^{\circ} \mathrm{C}$ was used because of the lower thermal stability of this IL. The ENIL fixed beds were used in three sorption-desorption cycle tests.

\section{Results and discussion}

\subsection{Preparation and characterization of ENILs}

The selection of ILs for this work (EtOHmimBF ${ }_{4}$, CholineNTf $_{2}$ and $(\mathrm{EtOH})_{3} \mathrm{MeNMeSO}_{4}$ ) was conducted taking into consideration that ILs with acidic character and low Henry constants of $\mathrm{NH}_{3}$ can lead to ENILs with high capacity for $\mathrm{NH}_{3}$ capture. Previous works indicated that the inclusion of hydrogen-bond donor groups, such 
Table 2 Physical and thermodynamic properties of the IL studied 22,23

\begin{tabular}{llllll}
\hline & $M_{\text {weight }},\left(\mathrm{g} \mathrm{mol}^{-1}\right)$ & $V_{\text {molecule }}{ }^{a},\left(\mathrm{~nm}^{3}\right)$ & Density, $\left(\mathrm{g} \mathrm{mL}^{-1}\right)$ & Viscosity, (mPa s) & Henry constant ${ }^{a},(\mathrm{MPa})$ \\
\hline EtOHmimBF $_{4}$ & 214 & 0.266 & $1.36\left(20^{\circ} \mathrm{C}\right)$ & $149\left(20^{\circ} \mathrm{C}\right)$ & 0.013 \\
CholineNTf $_{2}$ & 368 & 0.427 & $1.52\left(30^{\circ} \mathrm{C}\right)$ & $95\left(30^{\circ} \mathrm{C}\right)$ & $<10^{-4}$ \\
$(\text { EtOH })_{3} \mathrm{MeNMeSO}_{4}$ & 275 & 0.374 & $1.34\left(20^{\circ} \mathrm{C}\right)$ & $1492\left(20^{\circ} \mathrm{C}\right)$ & 0.011
\end{tabular}

${ }^{a} \mathrm{NH}_{3}$ absorption, calculated by COSMO-RS method at $T=25^{\circ} \mathrm{C}$.

as hydroxyl group, in the IL structure significantly increases the interaction with $\mathrm{NH}_{3}$, and thus its solubility. ${ }^{22,23}$ Table 2 collects the most relevant physical and thermodynamic properties of the task-specific ILs used in this work.

A set of ENILs based on EtOHmimBF 4 and different IL loads $\left(R_{0.5}, R_{1}, R_{2}\right.$ and $\left.R_{4}\right)$ were prepared with the view in analyzing their properties and behavior in $\mathrm{NH}_{3}$ capture. Additional ENILs incorporating a high load $\left(R_{4}\right)$ of CholineNTf $\mathrm{N}_{2}$ and $(\mathrm{EtOH})_{3}$ $\mathrm{MeNMeSO}_{4}$ were also prepared in order to also check the influence of the nature of the IL.

The SEM image of $\mathrm{C}_{\text {cap }}$ (Fig. 1A) showed regular spherical morphology and a mean diameter around $600 \mathrm{~nm}$. A wall thickness $c a .80 \mathrm{~nm}$ can be measured from TEM image (Fig. 1B). The TEM image (Fig. 1C) of the ENIL- $R_{4}$ prepared with EtOHmimBF $_{4}$, shows successful incorporation of the IL into de $\mathrm{C}_{\text {cap }}$ structure, both in the hollow core and in the porous carbon wall. The EA results in Table 3 also confirm the adequate incorporation of IL into the ENILs.
Adsorption-desorption isotherms of $\mathrm{N}_{2}$ at $-196{ }^{\circ} \mathrm{C}$ were used to analyze the porous structure of $\mathrm{C}_{\text {cap }}$ and ENILs, being the results collected in Table 3 . $\mathrm{C}_{\text {cap }}$ showed a highly developed porous structure $\left(A_{\mathrm{BET}}=1503 \mathrm{~m}^{2} \mathrm{~g}^{-1}\right)$, with high contributions of micro- and mesoporosity, as indicated by the high amount of nitrogen adsorbed in the whole relative pressure range. Fig. $2 \mathrm{~A}$ shows the isotherms obtained for ENILs with different loads of EtOHmimBF$_{4}$. The porosity available for nitrogen adsorption decreases clearly as the load of IL increases. In fact, for ENIL$R_{0.5}(33 \%$ of IL) a reduction of $65 \%$ in the BET surface area takes place (Table 3), whereas for ENIL- $R_{1}(50 \%$ of IL) only $13 \%$ of the initial BET surface area of the $\mathrm{C}_{\text {cap }}$ is still available for $\mathrm{N}_{2}$ adsorption. The BET surface area decreases to negligible values for $R_{2}$, and particularly for $R_{4}(80 \%$ of IL). Fig. $2 \mathrm{~B}$ shows that the loss of porosity takes place evenly in the whole range of porosity with the increase in the load of IL. Table 3 also summarizes the characteristics of the ENILs prepared with CholineNTf ${ }_{2}$ and

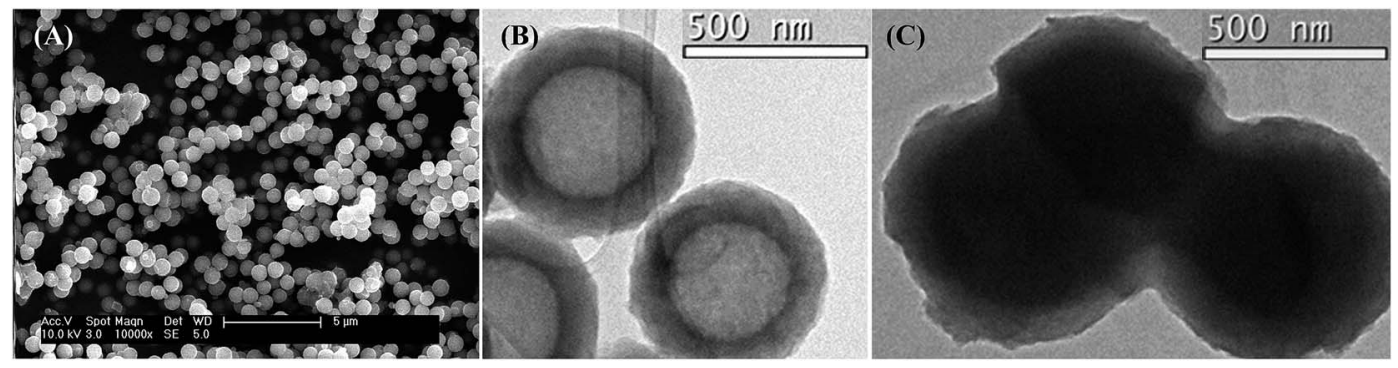

Fig. 1 (A) SEM images of $\mathrm{C}_{\text {cap }}$ and TEM images of (B) $\mathrm{C}_{\text {cap }}$ and (C) ENIL- $R_{4}$ prepared with EtOHmimBF 4 .

Table 3 Characterization of the $\mathrm{C}_{\text {cap }}$ and ENILs prepared with different load of IL

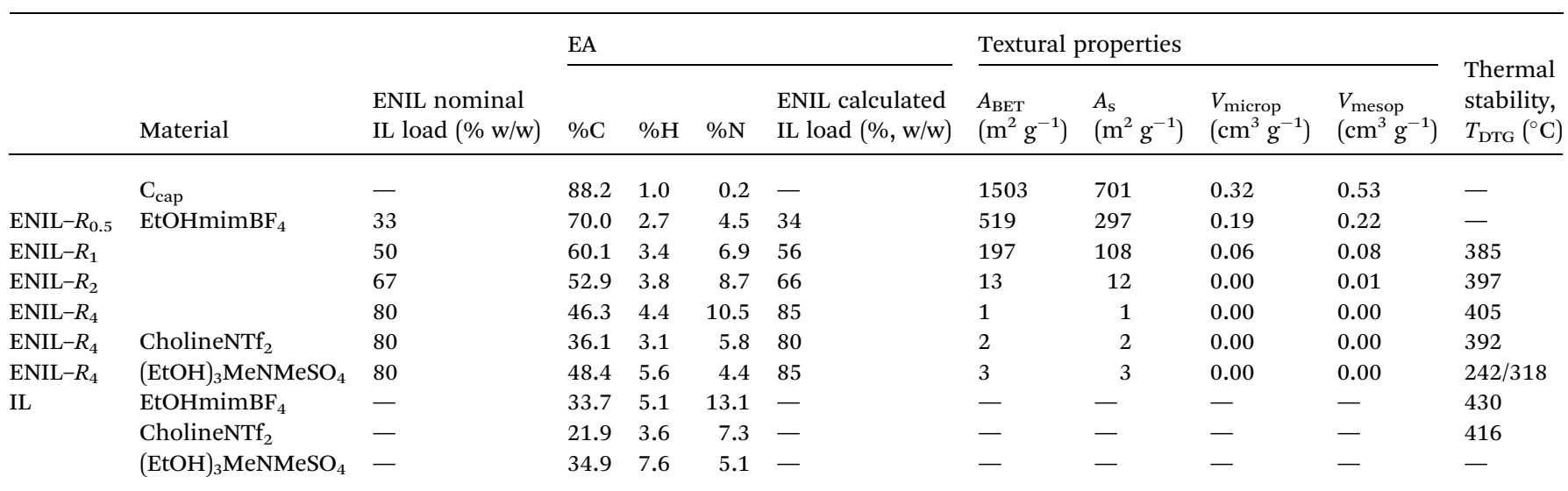



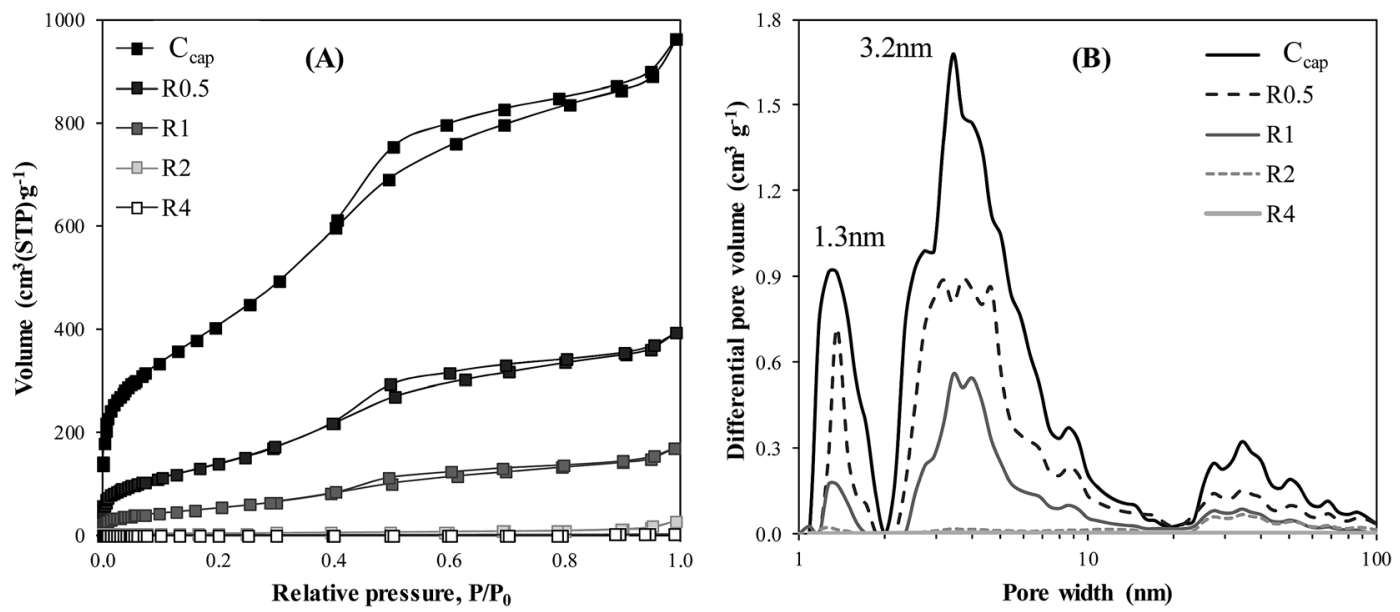

Fig. 2 (A) Nitrogen adsorption-desorption isotherms at $-196^{\circ} \mathrm{C}$ and (B) pore size distribution (1 to $100 \mathrm{~nm}$ ) of $\mathrm{C}_{\text {cap }}$ and ENILs prepared with increasing load of $\mathrm{EtOH}_{\mathrm{mimBF}}\left(R_{0.5}-R_{4}\right)$.

$(\mathrm{EtOH})_{3} \mathrm{MeNMeSO}_{4}$, showing also nearly total loss of porosity $\left(A_{\mathrm{BET}}<3 \mathrm{~m}^{2} \mathrm{~g}^{-1}\right)$ for $R_{4}$ independently of the IL used.

Thermal stability is also an important factor to be considered for the application of ENILs. Fig. 3A depicts the TGA curves of the neat IL EtOHmimBF ${ }_{4}$ and $\mathrm{C}_{\text {cap }}$. As can be seen, EtOHmimBF 4 starts to decompose around $340{ }^{\circ} \mathrm{C}$ and it is decomposed almost completely at $460^{\circ} \mathrm{C}$. $\mathrm{C}_{\text {cap }}$ exhibits a loss of weight lower than $10 \%$ in the temperature range considered, which can be ascribed to the gradual loss of surface chemical groups. The thermal stability of the ENILs prepared with EtOHmimBF $_{4}$ can be compared with that of the neat IL in Fig. 3B (see also Fig. 1S in ESI $\dagger$ for complete TGA data). Previous studies ${ }^{46,62}$ showed that the thermal stability of supported ILs can be remarkably affected by the nature of the support, with non-polar porous surfaces, such as activated carbon, leading more stable SILP than supports with acidic character, such as silica. Fig. $3 \mathrm{~B}$ and Table 3 (see $T_{\mathrm{DTG}}$ values) show that the thermal stability of ENIL materials is slightly lower than that of the neat IL, in agreement with the low support effect observed with carbon surfaces containing low concentration of polar functional groups, ${ }^{46}$ which is the case of $\mathrm{C}_{\text {cap }}$. In addition, it can be observed that an increase of the IL load results in higher thermal stability of the ENIL material, with a shift in the DTG degradation peak $\left(T_{\mathrm{DTG}}\right)$ from 385 to $405{ }^{\circ} \mathrm{C}$. This shift is probably related to the decreasing proportion of IL in contact with the support surface. Thus, ENIL- $R_{4}$ presents a thermal stability very close to that of the neat IL EtOHmimBF $\mathrm{m}_{4}$. Table 3 also summarizes the $T_{\mathrm{DTG}}$ for the ENIL- $R_{4}$ prepared with CholineNTf ${ }_{2}$ and (EtOH) ${ }_{3} \mathrm{MeNMeSO}_{4}$ (complete TGA curves in Fig. $2 \mathrm{~S}$ and $3 \mathrm{~S}$ in ESI $\dagger$ ). It can be concluded that ENILs, particularly $R_{4}$, present an adequate thermal stability to operate in the $30-200{ }^{\circ} \mathrm{C}$ range of sorption/desorption temperatures involved in the $\mathrm{NH}_{3}$ capture and bed regeneration processes.

\subsection{Capture experiments in fixed-bed column}

Fig. 4 depicts the $\mathrm{NH}_{3}$ breakthrough curves obtained using a packed bed of $\mathrm{C}_{\text {cap }}$ at temperatures of 30,45 and $60^{\circ} \mathrm{C}$. Table 4
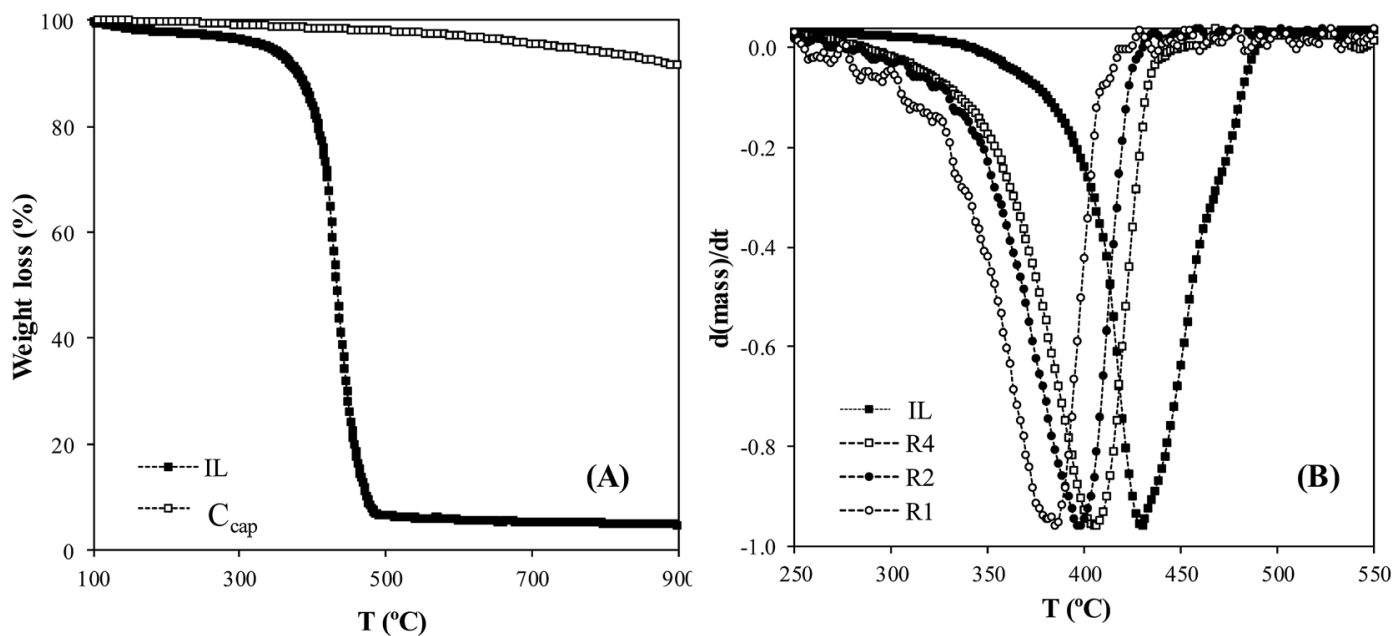

Fig. 3 (A) Dynamic thermogravimetric curve (TGA) of neat EtOHmimBF 4 and $\mathrm{C}_{\text {capi }}$ (B) normalized derivative thermogravimetric curve (DTG) of ENILs prepared with EtOHmimBF 4 and neat $\mathrm{EtOHmimBF}_{4}$ (nitrogen atmosphere and a heating rate of $10^{\circ} \mathrm{C} \mathrm{min}{ }^{-1}$ ). 


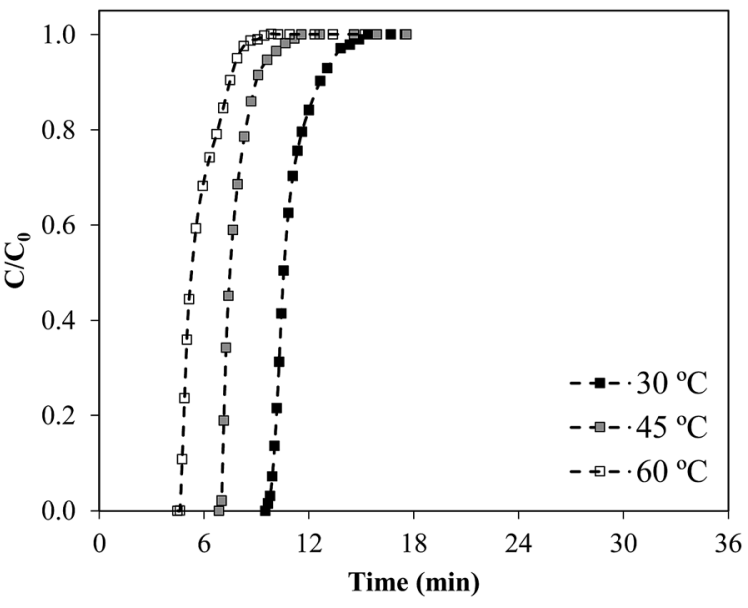

Fig. 4 Breakthrough curves of $\mathrm{NH}_{3}$ sorption by fixed bed of $\mathrm{C}_{\text {cap }}$ (2000 ppmv inlet $\mathrm{NH}_{3}$ concentration, $20 \mathrm{~mL} \mathrm{~min}^{-1}$ and a bed length of $5 \mathrm{~cm}$ ).

collects the operating conditions and the main results extracted from the $\mathrm{NH}_{3}$ capture experiments conducted, including the breakthrough time $\left(t_{\mathrm{b}}\right)$, the saturation capacity $\left(q_{\mathrm{s}}\right)$ calculated on different basis, and the length of mass transfer zone ( $\left.h_{\mathrm{MTZ}}\right)$. $\mathrm{C}_{\text {cap }}$ support presents a high $\mathrm{NH}_{3}$ uptake per mass of sorbent $\left(q_{\mathrm{s}, \mathrm{sorb}}=6.0 \mathrm{mg} \mathrm{g}^{-1}\right)$, equivalent and even higher than those reported for physical adsorption with ACs. ${ }^{63,64}$ The operating temperature has a remarkable effect on $\mathrm{NH}_{3}$ adsorption by $\mathrm{C}_{\text {cap }}$, with bed capacity decreasing by $\sim 40 \%$ when temperature increased from 30 to $60{ }^{\circ} \mathrm{C}$. This change is in agreement with the results obtained for $\mathrm{NH}_{3}$ adsorption with other ACs in bibliography. ${ }^{63,64}$ The length of mass transfer zone values (e.g. $h_{\mathrm{MTZ}}=1.5 \mathrm{~cm}$ at $30^{\circ} \mathrm{C}$ ) are close to the values reported for the adsorption of other solutes (chloromethanes, ethanol) on ACs. ${ }^{65,66}$ This reveals fast and favorable $\mathrm{NH}_{3}$ adsorption onto $\mathrm{C}_{\text {cap }}$, ascribable to the large contact surface area and low size of the submicrocapsules.

Fig. 5 presents the $\mathrm{NH}_{3}$ breakthrough curves obtained in fixed bed experiments using ENIL- $\mathrm{R}_{n}$ prepared with different loads of EtOHmimBF 4 , being the main results extracted from them and collected in Table 4. As can be seen, the incorporation of the IL into the $\mathrm{C}_{\text {cap }}$ support does not improve the sorption capacity per unit mass of sorbent $\left(q_{\mathrm{s} \text {,ENIL }}\right)$. However, due to filling of the pores of $\mathrm{C}_{\text {cap }}$ with $\mathrm{IL}$, the $\mathrm{NH}_{3}$ sorption capacity per bed volume unit $\left(q_{\mathrm{s}, \mathrm{V}} ; \mathrm{mg} \mathrm{\textrm {cm } ^ { - 3 }}\right)$ evidences the advantages of ENILs in terms of bed efficiency when compared to $\mathrm{C}_{\text {cap }}$. Thus, when the load of EtOHmimBF ${ }_{4}$ in the ENILs is increased, the total amount of $\mathrm{NH}_{3}$ captured by the bed was higher, with the breakthrough times increasing from 8.6 to 22.7 minutes for $R_{0.5}$ and $R_{4}$, respectively. These tests were carried out using approximately the same length of bed $(4.8-5.1 \mathrm{~cm})$, which

Table 4 Operating conditions and results for the capture of $\mathrm{NH}_{3}$ using packed beds of $\mathrm{C}_{\text {cap }}$ and ENILs (gas flow $20 \mathrm{~mL} \mathrm{~min}^{-1}$, atmospheric pressure)

\begin{tabular}{|c|c|c|c|c|c|c|c|c|c|c|}
\hline & & $T,\left({ }^{\circ} \mathrm{C}\right)$ & $\begin{array}{l}{\left[\mathrm{NH}_{3}\right]_{0},} \\
\text { (ppmv) }\end{array}$ & $h,(\mathrm{~cm})$ & $\begin{array}{l}m_{\mathrm{ENIL}} \\
(\mathrm{mg})\end{array}$ & $t_{\mathrm{b}},(\min )$ & $\begin{array}{l}q_{\mathrm{s}, \mathrm{V}}, \\
\left.(\mathrm{mg} \mathrm{cm})^{-3}\right)\end{array}$ & $\begin{array}{l}q_{\mathrm{s}, \mathrm{IL}}, \\
\left(\mathrm{mg} \mathrm{g}_{\mathrm{IL}}{ }^{-1}\right)\end{array}$ & $\begin{array}{l}q_{\mathrm{s}, \mathrm{ENIL}} \\
\left(\mathrm{mg} \mathrm{g}_{\mathrm{ENIL}}{ }^{-1}\right)\end{array}$ & $\begin{array}{l}h_{\mathrm{MTZ}}, \\
(\mathrm{cm})\end{array}$ \\
\hline $\mathrm{C}_{\text {cap }}$ & & 30 & 2000 & 4.8 & 52.2 & 9.9 & 0.52 & - & $6.0^{b}$ & 1.6 \\
\hline ENIL- $R_{1}$ & $\mathrm{EtOHmimBF}_{4}$ & 30 & 2000 & 5.0 & 119.6 & 11.6 & 0.61 & $-^{a}$ & 3.2 & 2.0 \\
\hline ENIL- $R_{2}$ & $\mathrm{EtOHmimBF}_{4}$ & 30 & 2000 & 5.1 & 164.7 & 12.8 & 0.77 & $-^{a}$ & 3.0 & 1.7 \\
\hline ENIL- $R_{4}$ & $\mathrm{EtOHmimBF}_{4}$ & 30 & 2000 & 4.8 & 216.4 & 22.7 & 1.18 & 4.1 & 3.3 & 1.6 \\
\hline $\mathrm{C}_{\text {cap }}$ & & 45 & 2000 & 5.0 & 49.2 & 7.0 & 0.42 & - & 5.4 & 1.8 \\
\hline ENIL- $R_{4}$ & $\mathrm{EtOHmimBF}_{4}$ & 45 & 2000 & 4.8 & 214.0 & 21.9 & 1.10 & 3.9 & 3.1 & 1.3 \\
\hline ENIL- $R_{4}$ & CholineNTf $_{2}$ & 45 & 2000 & 4.5 & 231.5 & 8.9 & 0.49 & 1.4 & 1.2 & 1.3 \\
\hline ENIL- $R_{4}$ & $(\mathrm{EtOH})_{3} \mathrm{MeNMeSO}{ }_{4}$ & 45 & 2000 & 4.0 & 207.7 & 7.1 & 0.50 & 1.5 & 1.2 & 1.8 \\
\hline $\mathrm{C}_{\text {cap }}$ & & 60 & 2000 & 5.0 & 50.0 & 4.9 & 0.30 & - & 3.8 & 2.1 \\
\hline ENIL- $R_{4}$ & $\mathrm{EtOHmimBF}_{4}$ & 60 & 2000 & 4.7 & 214.0 & 19.3 & 1.01 & 3.5 & 2.8 & 1.2 \\
\hline & & 30 & 1200 & 4.5 & 198.0 & 35.7 & 1.12 & 3.9 & 3.2 & 1.4 \\
\hline & & 30 & 1500 & 4.4 & 194.0 & 33.0 & 1.12 & 3.9 & 3.2 & 1.4 \\
\hline \multirow[t]{4}{*}{ ENIL- $R_{4}$} & CholineNTf $_{2}$ & 30 & 500 & 4.3 & 224.5 & 28.8 & 0.29 & 1.1 & 0.7 & 1.3 \\
\hline & & 30 & 800 & 4.3 & 225.0 & 19.6 & 0.42 & 1.3 & 1.0 & 1.4 \\
\hline & & 30 & 1200 & 4.4 & 222.5 & 9.9 & 0.44 & 1.3 & 1.1 & 1.5 \\
\hline & & 30 & 1500 & 4.4 & 225.8 & 9.6 & 0.45 & 1.4 & 1.1 & 1.5 \\
\hline \multirow[t]{4}{*}{ ENIL- $R_{4}$} & $(\mathrm{EtOH})_{3} \mathrm{MeNMeSO}{ }_{4}$ & 30 & 500 & 4.0 & 201.0 & 17.2 & 0.32 & 0.9 & 0.8 & 1.6 \\
\hline & & 30 & 800 & 4.0 & 197.0 & 19.9 & 0.51 & 1.7 & 1.3 & 1.7 \\
\hline & & 30 & 1200 & 4.0 & 200.5 & 15.8 & 0.56 & 1.8 & 1.4 & 1.7 \\
\hline & & 30 & 1500 & 4.0 & 200.9 & 13.9 & 0.60 & 1.9 & 1.5 & 1.8 \\
\hline
\end{tabular}

${ }^{a}$ Mixture of adsorption and absorption phenomena. ${ }^{36}{ }^{b}{ }_{\mathrm{s}, \mathrm{sorb}}\left(\mathrm{mg} \mathrm{g}_{\mathrm{C}_{\text {cap }}}\right.$ adsorbent $\left.{ }^{-1}\right)$. 


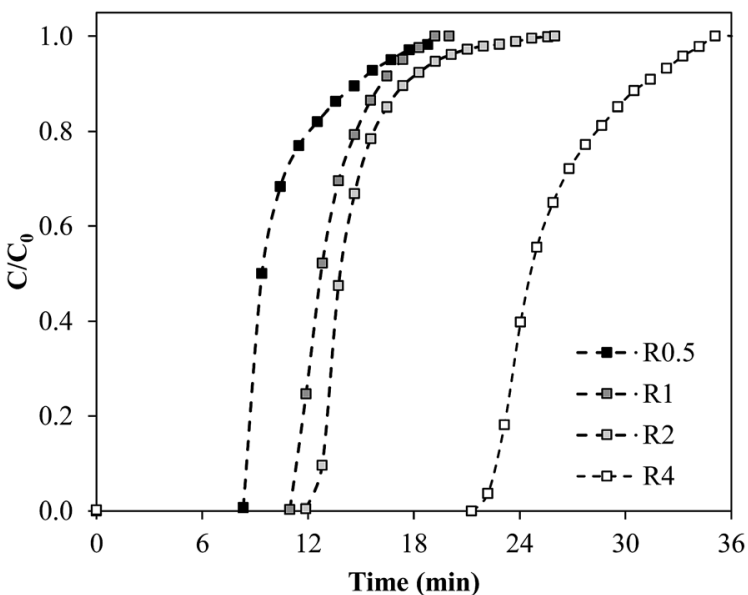

Fig. 5 Breakthrough curves of $\mathrm{NH}_{3}$ capture by ENILs prepared with different load of EtOHmimBF 4 (2000 ppmv inlet $\mathrm{NH}_{3}$ concentration, $20 \mathrm{~mL} \mathrm{~min}{ }^{-1}$ and $30^{\circ} \mathrm{C}$, bed length $5 \mathrm{~cm}$ ).

implied different ENIL mass (77.0-216.4 mg) because of differences in density caused by the different load of IL in the ENILs. As a result of it the ENIL- $R_{4}$ prepared with EtOHmimBF yielded much higher uptake of $\mathrm{NH}_{3}$ per bed volume unit $\left(q_{\mathrm{s}, \mathrm{V}}^{30}{ }^{\circ} \mathrm{C}, 2000 \mathrm{ppmv}=1.18 \mathrm{mg} \mathrm{cm}^{-3}\right)$ than the $\mathrm{C}_{\mathrm{cap}}\left(q_{\mathrm{s}, \mathrm{V}}^{30}{ }^{\circ} \mathrm{C}, 2000 \mathrm{ppmv}=\right.$ $\left.0.52 \mathrm{mg} \mathrm{cm} \mathrm{cm}^{-3}\right)$. In other words, ENILs lead to a higher bed efficiency thank to the incorporation of the IL solvent into the void porous structure of the support, in good agreement with previous results. ${ }^{53}$ Favorable conclusions are also achieved when comparing with other commercial $\mathrm{NH}_{3}$ sorbents tested in fixed bed under similar operating conditions (see Table 4): BAHIACARBON AC, $q_{\mathrm{s}, \mathrm{V}}=0.97 \mathrm{mg} \mathrm{cm}{ }^{-3}\left(\left[\mathrm{NH}_{3}\right]_{0}=1200 \mathrm{ppmv}\right.$, $\left.40{ }^{\circ} \mathrm{C}, 1 \mathrm{~atm}\right),{ }^{64}$ HAYCARB AC $q_{\mathrm{s}, \mathrm{V}}=0.56 \mathrm{mg} \mathrm{cm}^{-3}\left(\left[\mathrm{NH}_{3}\right]_{0}=\right.$ $\left.1000 \mathrm{ppmv}, 30{ }^{\circ} \mathrm{C}, 1 \mathrm{~atm}\right)^{67}$ and MAST AC $q_{\mathrm{s}, \mathrm{V}}=1.8 \mathrm{mg} \mathrm{cm} \mathrm{cm}^{-3}$ $\left(\left[\mathrm{NH}_{3}\right]_{0}=1000 \mathrm{ppmv}, 23{ }^{\circ} \mathrm{C}, 1 \mathrm{~atm}\right) .{ }^{68}$ It should be noted that increasing the surface acidity of these commercial adsorbents by chemical treatments may greatly enhance their $\mathrm{NH}_{3}$ adsorption capacity, ${ }^{67,68}$ but at the expense of lower mass transfer rates $^{67}$ and probably more difficult regeneration of exhausted adsorbent, due to strong acid-base chemical interactions between ammonia and the surface functional groups. ${ }^{68}$
It is noticeable that the $\mathrm{NH}_{3}$ sorption capacity per unit mass of IL of the ENIL- $R_{4}$ prepared with $\mathrm{EtOHmimBF}_{4}\left(q_{\mathrm{s}, \mathrm{IL}}=4.1 \mathrm{mg}\right.$ $\left.\mathrm{g}_{\mathrm{IL}}{ }^{-1}\right)$ is close to the absorption capacity of neat EtOHmimBF 4 $\left(q_{\mathrm{s}}^{30}{ }^{\circ} \mathrm{C}=4.40 \mathrm{mg} \mathrm{g}_{\mathrm{IL}}{ }^{-1}\right.$; see Fig. $\mathrm{S} 4$ in $\left.\mathrm{ESI} \dagger\right)$ obtained by gravimetric measurements at identical temperature and $\mathrm{NH}_{3}$ concentration. It indicates that the task-specific IL maintains its high $\mathrm{NH}_{3}$ absorption capacity after encapsulation.

Fig. 6 compares the breakthrough curves obtained for ENIL$R_{4}$ prepared with the different ILs (EtOHmimBF 4 , CholineNTf ${ }_{2}$ and $\left.(\mathrm{EtOH})_{3} \mathrm{MeNMeSO}_{4}\right)$ at temperatures of 30,45 and $60{ }^{\circ} \mathrm{C}$. The $\mathrm{NH}_{3}$ capacity per bed volume unit $\left(q_{\mathrm{s}, \mathrm{V}} ; \mathrm{mg} \mathrm{cm}{ }^{-3}\right.$, Table 4$)$ at $30{ }^{\circ} \mathrm{C}$ increases in the order $\mathrm{EtOHmimBF}_{4}>(\mathrm{EtOH})_{3}$ $\mathrm{MeNMeSO}_{4}>\mathrm{CholineNTf}_{2}$, in good agreement with the absorption capacities of the corresponding neat ILs (see Fig. S4 in ESI $\dagger$ ). This confirms that the selection of the task-specific IL also plays a crucial role in the $\mathrm{NH}_{3}$ capture by ENIL in fixed-bed operation.

Increasing the temperature from 30 to $60{ }^{\circ} \mathrm{C}$ resulted in lower bed capacities, as can be seen from the shift of the breakthrough curves to shorter times and the parameters summarized in Table 4 . It should be remarked that the $\mathrm{NH}_{3}$ uptakes achieved with ENILs prepared with EtOHmimBF 4 and $(\mathrm{EtOH})_{3} \mathrm{MeNMeSO}_{4}$ were less affected by temperature than in the case of $\mathrm{C}_{\text {cap }}$ (Fig. 4). The low influence of temperature may be ascribed to the low enthalpy associated to the physical absorption of $\mathrm{NH}_{3}$ (ca. $-5 \mathrm{~kJ} \mathrm{~mol}^{-1}$ for IL EtOHmimBF $\left.{ }_{4}{ }^{22}\right)$ in comparison with the physical adsorption of $\mathrm{NH}_{3}$ on $\mathrm{AC}(\mathrm{ca} .-25$ $\left.\mathrm{kJ} \mathrm{mol}{ }^{-1},{ }^{63}\right)$. Therefore, the bed efficiency $\left(q_{\mathrm{s}, \mathrm{V}}\right.$ in $\left.\mathrm{mg} \mathrm{cm}^{-3}\right)$ is less affected by temperature in the case of these ENILs $(\sim 15 \%$ variation in $30-60{ }^{\circ} \mathrm{C}$ temperature range $)$ than for $\mathrm{C}_{\text {cap }}(\sim 40 \%$ variation in $30-60{ }^{\circ} \mathrm{C}$ temperature range) and more flexibility can be achieved for operation at different temperatures. This adverse temperature effect on $\mathrm{NH}_{3}$ adsorption has been previously observed in commercial carbonaceous adsorbents: BAHIACARBON AC $\left(\sim 50 \%\right.$ variation in $40-80{ }^{\circ} \mathrm{C}$ temperature range $)^{64}$ and MERCK AC ( $\sim 50 \%$ variation in $25-55{ }^{\circ} \mathrm{C}$ temperature range). ${ }^{63}$ The ENIL prepared with CholineNTf ${ }_{2}$ is barely affected by the temperature in the range considered. This behavior is related to the fact that CholineNTf $\mathrm{Nelts}_{2}$ at $30{ }^{\circ} \mathrm{C}^{69}$ and the solid state polymorphism can affect the capture experiments at surrounding temperatures.
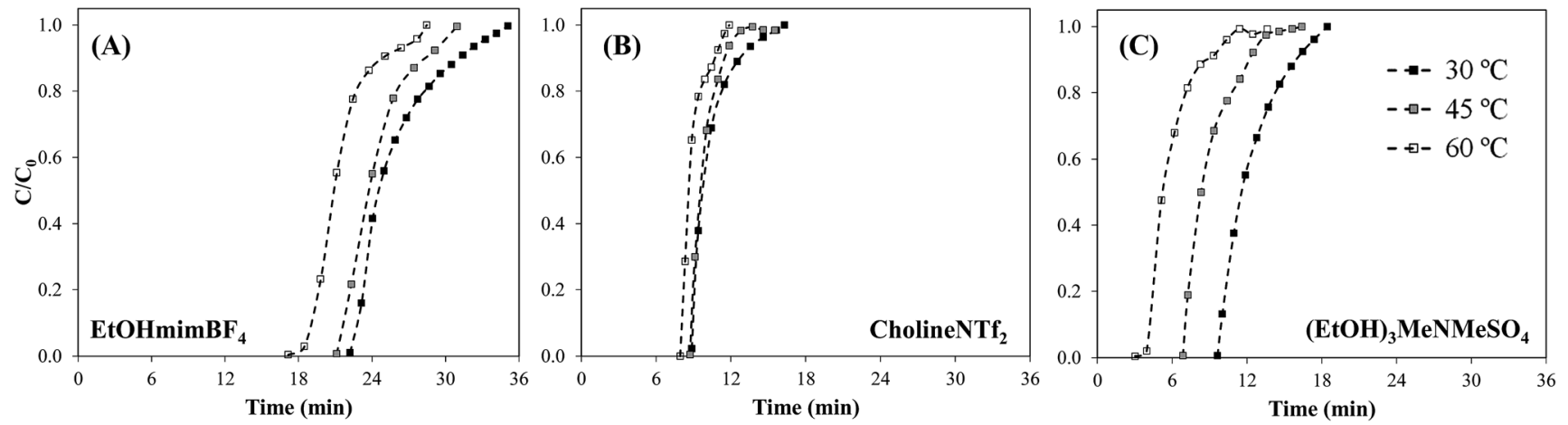

Fig. 6 Breakthrough curves of $\mathrm{NH}_{3}$ sorption on $\mathrm{ENIL}-\mathrm{R}_{4}$ prepared with (A) EtOHmimBF 4 (B) CholineNTf $\mathrm{CH}_{2}$ and $(\mathrm{C})(\mathrm{EtOH})_{3} \mathrm{MeNMeSO}_{4}(2 \mathrm{OOO}$

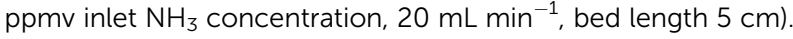




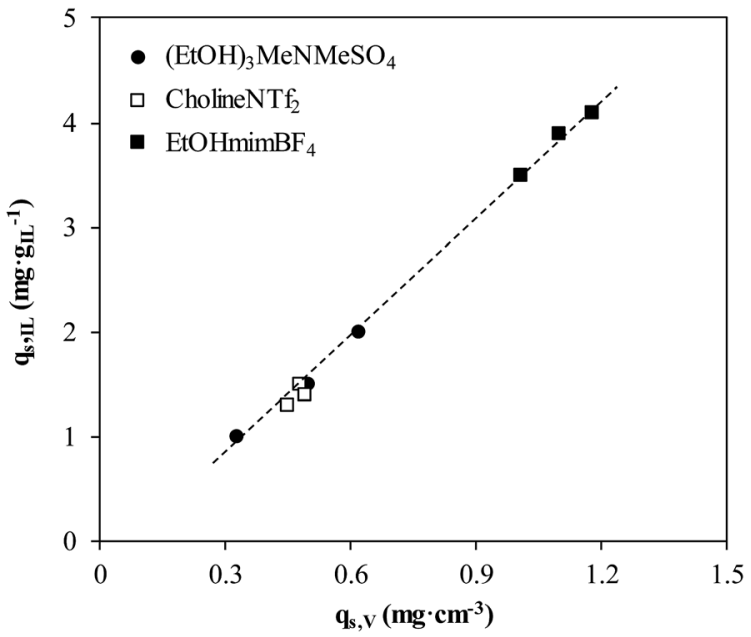

Fig. $7 \quad \mathrm{NH}_{3}$ sorption capacity $\mathrm{mg} \mathrm{g}_{\mathrm{IL}}{ }^{-1}$ versus sorption capacity in $\mathrm{mg}$ $\mathrm{cm}^{-3}$ for different ENIL-R $\left(30-60{ }^{\circ} \mathrm{C}, 2000\right.$ ppmv inlet $\mathrm{NH}_{3}$ concentration, $20 \mathrm{~mL} \mathrm{~min}^{-1}$ ).

Fig. 7 compares the $\mathrm{NH}_{3}$ sorption capacity of ENILs in terms of the amount retained per $\mathrm{g}$ of IL $\left(q_{\mathrm{s}, \mathrm{IL}} ; \mathrm{mg} \mathrm{g}_{\mathrm{IL}}{ }^{-1}\right)$ and the amount retained per bed volume unit $\left(q_{\mathrm{s}, \mathrm{V}} ; \mathrm{mg} \mathrm{cm}^{-3}\right)$. As can be seen, the relationship between these two parameters is almost linear, indicating that the absorption capacity of neat ILs can be considered as the main reference parameter for selecting ILs to prepare effective ENIL sorbents for a specific gas treatment. This linear relationship is also nearly independent of the IL used, since the three ones here considered have similar density (Table 2).

Fig. 8 depicts the $\mathrm{NH}_{3}$ sorption isotherms $\left(q_{\mathrm{s}}, \mathrm{mg} \mathrm{g}_{\mathrm{ENIL}}{ }^{-1}\right)$ at $30{ }^{\circ} \mathrm{C}$ for ENILs $-R_{4}$ prepared with $\mathrm{EtOHmimBF}_{4}$, $(\mathrm{EtOH})_{3}$ $\mathrm{MeNMeSO}_{4}$ and CholineNTf ${ }_{2}$, as calculated from the

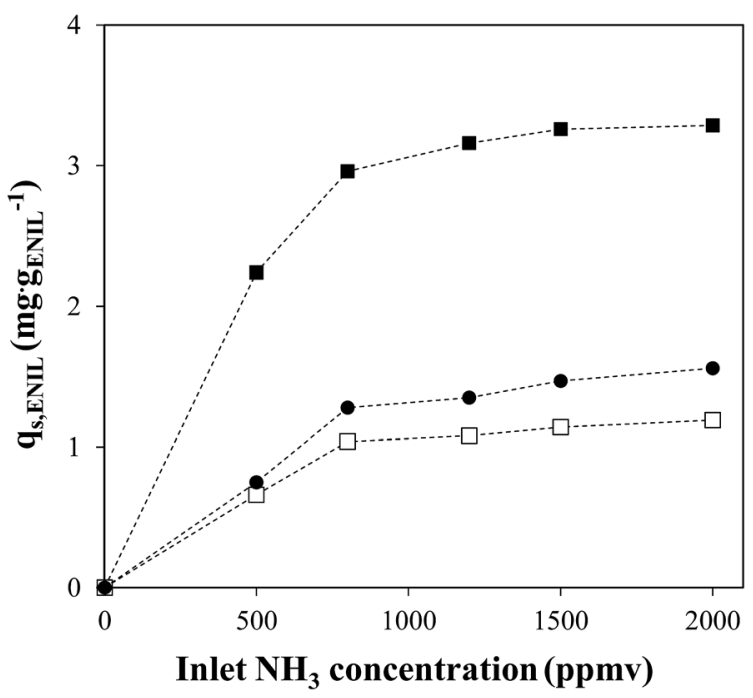

Fig. 8 Experimental sorption isotherm obtained from breakthrough curves using different inlet $\mathrm{NH}_{3}$ concentration and $\mathrm{ENIL}-R_{4}$ prepared

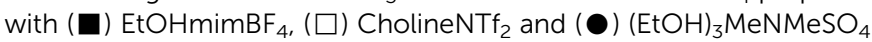
$\left(20 \mathrm{~mL} \mathrm{~min}{ }^{-1}\right.$, and $30^{\circ} \mathrm{C}$ ). breakthrough curves obtained at different $\mathrm{NH}_{3}$ inlet concentration (Fig. 5S of ESI $\dagger$ ). The amount of ammonia retained generally increases with increasing inlet $\mathrm{NH}_{3}$ partial pressures, in concordance with the absorption isotherms obtained for neat ILs. ${ }^{2,23}$ The results show again the significantly higher $\mathrm{NH}_{3}$ sorption capacity of the ENIL- $R_{4}$ prepared with EtOHmimBF 4 .

The length of mass transfer zone $\left(h_{\mathrm{MTZ}}\right)$ is an additional parameter of interest to evaluate the performance of $\mathrm{NH}_{3}$ capture by ENILs. The values obtained ENIL (see Table 4) indicate that, interestingly, the incorporation of IL into the $\mathrm{C}_{\text {cap }}$ has only minor effect on the slope of breakthrough curves and $h_{\mathrm{MTZ}}$ values at $30{ }^{\circ} \mathrm{C}$, showing that the good mass transfer conditions are maintained. Increasing the sorption temperature evidences additional advantages of ENILs, since $h_{\mathrm{MTZ}}$ decreased for all ENIL sorbents prepared. This effect is assignable to the higher $\mathrm{NH}_{3}$ diffusivity in ILs at higher temperatures. ${ }^{22,23}$ On the contrary, $h_{\mathrm{MTZ}}$ increases with temperature for $\mathrm{C}_{\text {cap }}$ (see Table 4), which is the commonly reported effect of temperature on the adsorption of gases by porous carbons. ${ }^{66}$ In fact, comparison to available data of $\mathrm{NH}_{3}$ fixed bed adsorption using commercial AC (BAHIACARBON, $\left[\mathrm{NH}_{3}\right]_{0}=1200 \mathrm{ppmv}, 1$ atm $)^{64}$ leads to similar conclusions, with estimated $h_{\mathrm{MTZ}}$ values of 1.8 and $2.8 \mathrm{~cm}$ at 40 and $80{ }^{\circ} \mathrm{C}$, respectively.

\subsection{Process reversibility}

The last step in this study was the evaluation of the regeneration of the exhausted ENILs, since it is an important issue regarding the potential application to $\mathrm{NH}_{3}$ capture. Fig. 9 shows the $\mathrm{NH}_{3}$ capture capacities $\left(q_{\mathrm{s}}\right.$, ENIL, $\left.\mathrm{mg} \mathrm{g}_{\mathrm{ENIL}}{ }^{-1}\right)$ of the ENILs prepared with the three ILs $\left(\mathrm{EtOHmimBF}_{4}, \mathrm{CholineNTf}_{2}\right.$ and $(\mathrm{EtOH})_{3}$ $\mathrm{MeNMeSO}_{4}$ ), calculated from breakthrough curves obtained in 3 successive capture-regeneration cycles. As can be seen, the sorption capacity of the ENILs remains nearly unaltered after the regeneration, thus showing the reusability of the bed. The

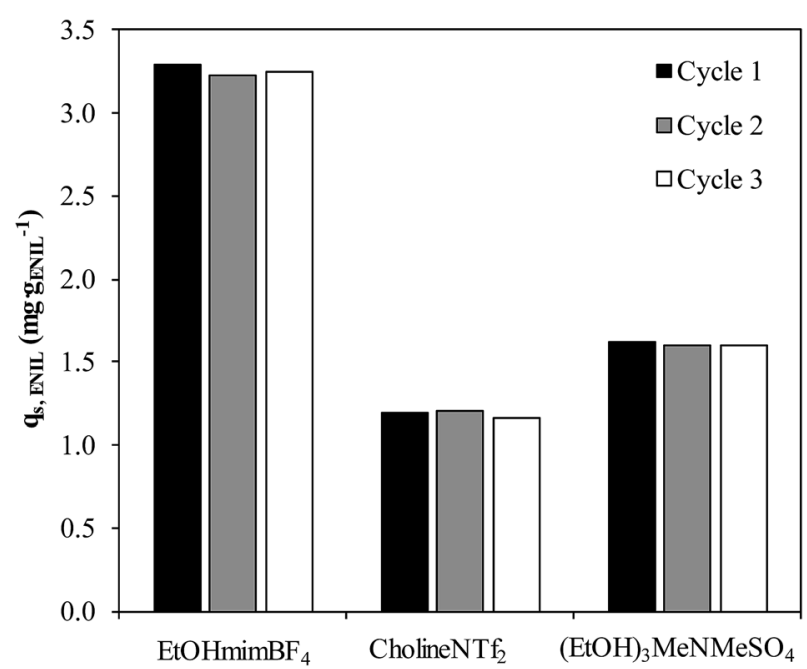

Fig. $9 \mathrm{NH}_{3}$ capture by ENIL-R $R_{4}$ prepared with the selected ILs in three consecutive capture/regeneration cycles (capture: $30^{\circ} \mathrm{C}, 1 \mathrm{~atm}, 2000$ ppmv, $20 \mathrm{~mL} \mathrm{~min}{ }^{-1}$; regeneration $150-200^{\circ} \mathrm{C}$, nitrogen atmosphere,

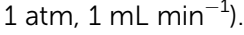


effective regeneration is another main advantage of ENILs to conventional adsorbents, since the desorption of $\mathrm{NH}_{3}$ from porous solid is a main concern. ${ }^{63}$

\section{Conclusions}

Encapsulated ionic liquids (ENILs) were specifically designed for $\mathrm{NH}_{3}$ capture from gas effluent, with further recovery of this compound, and their performance was evaluated by means of fixed bed experiments. The confinement of task-specific ILs into the carbon submicrocapsules resulted in ENILs with high IL content (up to $85 \% \mathrm{w} / \mathrm{w}$ ), high $\mathrm{NH}_{3}$ uptake capacity and high thermal stability (this last very close to that of neat IL). The incorporation of the ILs into the carbon submicrocapsules hollow space increased the efficiency of the bed (capacity per bed volume unit), respect to the benchmark carbonaceous adsorbent $\left(\mathrm{C}_{\text {cap }}\right.$ or commercial activated carbons). The large surface contact area of submicrocapsule particles promotes high mass transfer rates for $\mathrm{NH}_{3}$ sorption in ENILs. As a result, the lengths of the mass transfer zone obtained in fixed bed experiments with ENILs are similar or even shorter than those obtained with common adsorbents, indicating an efficient use of ENILs in the fixed bed. The application of ENILs in fixed bed operations may be particularly advantageous at higher temperatures, from both thermodynamic and kinetic points of view, respect to carbonaceous adsorbents. In addition, ENILs were successfully regenerated under mild conditions and used in successive $\mathrm{NH}_{3}$ capture-desorption cycles, without loss of operation efficiency. This a clear advantage respect to common gas adsorbents, which in general have problems of regeneration at mild conditions. The current results present ENILs as new separating agents with promising characteristics for future practical applications.

\section{Acknowledgements}

The authors are grateful to Comunidad de Madrid (project S2013-MAE-2800), Ministerio de Economia y Competitividad of Spain (Project CTQ2014-52288-R) and European Union (EXIL COST Action CM1206) for financial support.

\section{References}

1 T. H. Misselbrook, B. F. Pain and D. M. Headon, Estimates of ammonia emission from dairy cow collecting yards, J. Agric. Eng. Res., 1998, 71, 127-135.

2 T. H. Misselbrook, T. J. Van der Weerden, B. F. Pain, S. C. Jarvis, B. J. Chambers and K. A. Smith, Ammonia emission factors for UK agriculture, Atmos. Environ., 2000, 34, 871-880.

3 M. A. Sutton and D. Fowler, Introduction: fluxes and impacts of atmospheric ammonia on national, landscape and farm scales, Environ. Pollut., 2002, 119, 7-8.

4 T. H. Misselbrook, J. Webb and S. L. Gilhespy, Ammonia emissions from outdoor concrete yards used by livestock quantification and mitigation, Atmos. Environ., 2006, 40, 6752-6763.
5 M. A. Sutton, J. W. Erisman, F. Dentener and D. Moeller, Ammonia in the environment: From ancient times to the present, Environ. Pollut., 2008, 156, 583-604.

$6 \mathrm{~J}$. Arogo, P. W. Westerman and A. J. Heber, A review of ammonia emissions from confined swine feeding operations, Trans. ASAE, 2003, 46, 805-817.

7 W. B. Faulkner and B. W. Shaw, Review of ammonia emission factors for United States animal agriculture, Atmos. Environ., 2008, 42, 6567-6574.

8 P. M. Ndegwa, A. N. Hristov, J. Arogo and R. E. Sheffield, A review of ammonia emission mitigation techniques for concentrated animal feeding operations, Biosyst. Eng., 2008, 100, 453-469.

9 D. R. Macfarlane, N. Tachikawa, M. Forsyth, J. M. Pringle, P. C. Howlett, G. D. Elliott, J. H. Davis, M. Watanabe, P. Simon and C. A. Angell, Energy applications of ionic liquids, Energy Environ. Sci., 2014, 7, 232-250.

10 C. Hardacre and V. Parvulescu, Catalysis in Ionic Liquids From Catalyst Synthesis to Application, The Royal Society of Chemistry, 2014.

11 Z. Lei, C. Dai and B. Chen, Gas solubility in ionic liquids, Chem. Rev., 2014, 114, 1289-1326.

12 M. Hasib-ur-Rahman, M. Siaj and F. Larachi, Ionic liquids for $\mathrm{CO}_{2}$ capture-Development and progress, Chem. Eng. Process., 2010, 49, 313-322.

13 M. Gonzalez-Miquel, J. Palomar and F. Rodriguez, Selection of Ionic Liquids for Enhancing the Gas Solubility of Volatile Organic Compounds, J. Phys. Chem. B, 2013, 117, 296-306.

14 A. Yokozeki and M. B. Shiflett, Ammonia solubilities in room-temperature ionic liquids, Ind. Eng. Chem. Res., 2007, 46, 1605-1610.

15 A. Yokozeki and M. B. Shiflett, Water Solubility in Ionic Liquids and Application to Absorption Cycles, Ind. Eng. Chem. Res., 2010, 49(19), 9496-9503.

16 S. Q. Liang, W. Chen, K. Cheng, Y. Guo and X. Gui. The latent application of ionic liquids in absorption refrigeration, Applications of Ionic Liquids in Science and Technology, ed. P. S. Handy, 2011.

17 F. Llovell, R. M. Marcos, N. MacDowell and L. F. Vega, Modeling the Absorption of Weak Electrolytes and Acid Gases with Ionic Liquids Using the Soft-SAFT Approach, $J$. Phys. Chem. B, 2012, 116, 7709-7718.

18 L. Chen, D. Huang, Y. Zhang, T. Dong, C. Zhou, S. Ren, Y. Chi and G. Chen, Ultrasensitive gaseous $\mathrm{NH}_{3}$ sensor based on ionic liquid-mediated signal-on electrochemiluminescence, Analyst, 2012, 137, 3514-3519.

19 M. Khamooshi, K. Parham and U. Atikol, Overview of Ionic Liquids Used as Working Fluids in Absorption Cycles, Adv. Mech. Eng., 2013, 1-7.

20 M. Lorenzo, M. Vilas, P. Verdía, M. Villanueva, J. Salgado and E. Tojo, Long-term thermal stabilities of ammonium ionic liquids designed as potential absorbents of ammonia, $R S C$ Adv., 2015, 5, 41278-41284.

21 Y. Shichao, Z. Jie, L. Zhenhua, B. Jie, Y. Yunfeng and P. Qin, Modeling and experimental studies of ammonia absorption in a spray tower, Korean J. Chem. Eng., 2016, 33, 63-72. 
22 J. Palomar, M. Gonzalez-Miquel, J. Bedia, F. Rodriguez and J. J. Rodriguez, Task-specific ionic liquids for efficient ammonia absorption, Sep. Purif. Technol., 2011, 82, 43-52.

23 J. Bedia, J. Palomar, M. Gonzalez-Miquel, J. Bedia, F. Rodriguez and J. J. Rodriguez, Screening ionic liquids as suitable ammonia absorbents on the basis of thermodynamic and kinetic analysis, Sep. Purif. Technol., 2012, 95, 188-195.

24 E. Ruiz, V. R. Ferro, J. de Riva, D. Moreno and J. Palomar, Evaluation of ionic liquids as absorbents for ammonia absorption refrigeration cycles using COSMO-based process simulations, Appl. Energy, 2014, 123, 281-291.

25 Y. Chen, W. Han and H. Jin, Proposal and analysis of a novel heat-driven absorption-compression refrigeration system at low temperatures, Appl. Energy, 2015, 75, 560-565.

26 S. Popp, A. Bösmann, R. Wölfe and P. Wasserscheid, Screening of Ionic Liquid/ $\mathrm{H}_{2} \mathrm{O}$ Working Pairs for Application in Low Temperature Driven Sorption Heat Pump Systems, ACS Sustainable Chem. Eng., 2015, 3(4), 750-757.

27 Q. Gan, D. Rooney, M. Xue, G. Thompson and Y. Zou, An experimental study of gas transport and separation properties of ionic liquids supported on nanofiltration membranes, J. Membr. Sci., 2006, 280, 948-956.

28 P. Sun and D. W. Armstrong, Ionic liquids in analytical chemistry, Anal. Chim. Acta, 2010, 661, 1-16.

29 J. de Riva, V. R. Ferro, L. Del Olmo, E. Ruiz, R. Lopez and J. Palomar, Statistical refinement and fitting of experimental viscosity-to-temperature data in ionic liquids, Ind. Eng. Chem. Res., 2014, 53, 10475-10484.

30 A. Riisager, R. Fehrmann, M. Haumann and P. Wasserscheid, Supported Ionic Liquid Phase (SILP) catalysis: an innovative concept for homogeneous catalysis in continuous fixed-bed reactors, Eur. J. Inorg. Chem., 2006, 4, 695-706.

31 L. Vidal, M. Riekkola and A. Canals, Ionic liquid-modified materials for solid-phase extraction and separation: a review, Anal. Chim. Acta, 2012, 715, 19-41.

32 H. Li, P. S. Bhadury, B. A. Song and S. Yang, Immobilized functional ionic liquids: efficient, green, and reusable catalysts, RSC Adv., 2012, 2, 12525-12551.

33 T. Selvam, A. Machoke and W. Schwieger, Supported ionic liquids on non-porous and porous inorganic materialsa topical review, Appl. Catal., A, 2012, 445-446, 92-101.

34 M. J. Schneider, M. Haumann and P. Wasserscheid, Asymmetric hydrogenation of methyl pyruvate in the continuous gas phase using Supported Ionic Liquid Phase (SILP) catalysis, J. Mol. Catal. A: Chem., 2013, 376, 103-110.

35 M. J. Schneider, M. Lijewski, R. Woelfel, M. Haumann and P. Wasserscheid, Continuous Gas-Phase Hydroaminomethylation using Supported Ionic Liquid Phase Catalysts, Angew. Chem., Int. Ed., 2013, 52, 6996-6999.

36 F. T. U. Kohler, D. Roth, E. Kuhlmann, P. Wasserscheid and M. Haumann, Continuous gas-phase desulfurisation using supported ionic liquid phase (SILP) materials, Green Chem., 2010, 12, 979-984.
37 H. Kolding, R. Fehrmann and A. Riisager, $\mathrm{CO}_{2}$ Capture technologies: Current status and new directions using supported ionic liquid phase (SILP) absorbers, Sci. China: Chem., 2012, 55, 1648-1656.

38 L. A. Banu, D. Wang and R. E. Baltus, Effect of Ionic Liquid Confinement on Gas Separation Characteristics, Energy Fuels, 2013, 27, 4161-4166.

39 H. Klefer, D. Roth, I. Eckle, C. Schrage, B. Bohringer, M. Haumann and P. Wasserscheid, Continuous Purification of Gases Using SILP Materials, Chem. Ing. Tech., 2014, 85, 92-96.

40 N. A. Khan, Z. Hasan and S. H. Jhung, Ionic Liquids Supported on Metal-Organic Frameworks: Remarkable Adsorbents for Adsorptive Desulfurization, Chem.-Eur. J., 2014, 20, 376-380.

41 S. Y. Chen, C. C. Han, C. H. Tsai, J. Huang and Y. W. ChenYang, Effect of morphological properties of ionic liquidtemplated mesoporous anatase $\mathrm{TiO}_{2}$ on performance of PEMFC with Nafion/TiO ${ }_{2}$ composite membrane at elevated temperature and low relative humidity, J. Power Sources, 2007, 171, 363-372.

42 M. Zhang, et al., One-pot synthesis of ordered mesoporous silica encapsulated polyoxometalate-based ionic liquids induced efficient desulfurization of organosulfur in fuel, RSC Adv., 2015, 5, 76048-76056.

43 I. H. Arellano, J. Huang and P. Pendleton, High capacity $\mathrm{CO}_{2}$ sorbents based on zinc-functionalized ionic liquid confined in morphologically diverse porous matrices, $R S C A d v ., 2015$, 5, 65074-65083.

44 V. Hiremath, A. H. Jadhav, H. Lee, S. Kwon and J. G. Seo, Highly reversible $\mathrm{CO}_{2}$ capture using amino acid functionalized ionic liquids immobilized on mesoporous silica, Chem. Eng. J., 2016, 287, 602-617.

45 A. Erto, A. Silvestre-Albero, J. Silvestre-Albero, F. RodriguezReinoso, M. Balsamo, A. Lancia and F. Montagnaro, Carbon-supported ionic liquids as innovative adsorbents for $\mathrm{CO}_{2}$ separation from synthetic flue-gas, J. Colloid Interface Sci., 2015, 448, 41-50.

46 J. Lemus, J. Palomar, M. A. Gilarranz and J. J. Rodriguez, Characterization of Supported Ionic Liquid Phase (SILP) materials prepared from different supports, Adsorption, 2011, 17, 561-571.

47 F. Shi, Q. H. Zhang, D. M. Li and Y. Q. Deng, Silica-gelconfined ionic liquids: a new attempt for the development of supported nanoliquid catalysis, Chem.-Eur. J., 2005, 11, 5279-5288.

48 J. Zhang, Q. Zhang, X. Li, S. Liu, Y. Ma, F. Shi and Y. Deng, Nanocomposites of ionic liquids confined in mesoporous silica gels: preparation, characterization and performance, Phys. Chem. Chem. Phys., 2010, 12, 1971-1981.

49 L. C. Bradley and M. Gupta, Encapsulation of Ionic Liquids within Polymer Shells via Vapor Phase Deposition, Langmuir, 2012, 28, 10276-10280.

50 M. Buaki-Sogo, H. Garcia and C. Aprile, Imidazolium-based silica microreactors for the efficient conversion of carbon dioxide, Catal. Sci. Technol., 2015, 5, 1222-1230. 
51 E. Weiss, D. Gertopski, M. K. Gupta and R. Abu-Reziq, Encapsulation of ionic liquid BMIm·PF6 within polyurea microspheres, React. Funct. Polym., 2015, 96, 32-38.

52 B. Yang, F. Zhou, S. Liu, P. Wang, A. S. Alshammaric and Y. Deng, Interaction between $\mathrm{CO}_{2}$ and ionic liquids confined in the nanopores of SAPO-11, RSC Adv., 2015, 5, $48908-48915$.

53 J. Palomar, J. Lemus, N. Alonso-Morales, J. Bedia, M. A. Gilarranz and J. J. Rodriguez, Encapsulated ionic liquids (ENILs): from continuous to discrete liquid phase, Chem. Commun., 2012, 48, 10046-10048.

54 S. B. Yoon, K. Sohn, J. Y. Kim, C. Shin, J. Yu and T. Hyeon, Fabrication of Carbon Capsules with Hollow Macroporous Core/Mesoporous Shell Structures, Adv. Mater., 2002, 14, 19-21.

55 P. Valle-Vigon, M. Sevilla and A. B. Fuertes, Synthesis of Uniform Mesoporous Carbon Capsules by Carbonization of Organosilica Nanospheres, Chem. Mater., 2010, 22, 25262533.

56 N. Alonso-Morales, M. A. Gilarranz, J. Palomar, J. Lemus, F. Heras and J. J. Rodriguez, Preparation of hollow submicrocapsules with a mesoporous carbon shell, Carbon, 2013, 59, 430-438.

57 J. Palomar, J. Lemus, M. A. Gilarranz and J. J. Rodriguez, Adsorption of ionic liquids from aqueous effluents by activated carbon, Carbon, 2009, 47, 1846-1856.

58 J. Lemus, J. Palomar, F. Heras, M. A. Gilarranz and J. J. Rodriguez, Developing criteria for the recovery of ionic liquids from aqueous phase by adsorption with activated carbon, Sep. Purif. Technol., 2012, 97, 11-19.

59 J. Lemus, J. Palomar, M. A. Gilarranz and J. J. Rodriguez, On the Kinetics of Ionic Liquid Adsorption onto Activated Carbons from Aqueous Solution, Ind. Eng. Chem. Res., 2013, 52, 2969-2976.

60 F. T. U. Kohler, S. Popp, H. Klefer, I. Eckle, C. Schrage, B. Böhringer, D. Roth, M. Haumann and P. Wasserscheid, Supported ionic liquid phase (SILP) materials for removal of hazardous gas compounds-efficient and irreversible $\mathrm{NH}_{3}$ adsorption, Green Chem., 2014, 16, 3560-3568.

$61 \mathrm{~K}$. Sing, Adsorption methods for the characterization of porous materials, Adv. Colloid Interface Sci., 1998, 76, 3-11.

62 M. P. Singh, R. K. Singh and S. Chandra, Ionic liquids confined in porous matrices: physicochemical properties and applications, Prog. Mater. Sci., 2014, 64, 73-120.

63 J. Helminen, J. Helenius, E. Paatero and I. Turunen, Comparison of sorbents and isotherm models for $\mathrm{NH}_{3}$-gas separation by adsorption, AIChE J., 2000, 46(8), 1541-1555.

64 C. C. Rodrigues, D. Moraes Jr, S. W. da Nobrega and M. G. Barboza, Ammonia adsorption in a fixed bed of activated carbon, Bioresour. Technol., 2007, 98, 886-891.

65 J. F. Vivo-Vilches, E. Bailón-García, A. F. Pérez-Cadenas, F. Carrasco-Marín and F. J. Maldonado-Hódar, Tailoring activated carbons for the development of specific adsorbents of gasoline vapors, J. Hazard. Mater., 2013, 263, 533-540.

66 J. Lemus, M. Martin-Martinez, J. Palomar, L. Gomez-Sainero, M. A. Gilarranz and J. J. Rodriguez, Removal of chlorinated organic volatile compounds by gas phase adsorption with activated carbon, Chem. Eng. J., 2012, 211-212, 246-254.

67 C. H. Huang, H. S. Li and C. H. Chen, Effect of surface acidic oxides of activated carbon on adsorption of ammonia, $J$. Hazard. Mater., 2008, 150, 523-527.

68 M. Goncales, L. Sanchez-Garcia, E. O. Jardim, J. SilvestreAlbero and F. Rodriguez-Reinoso, Ammonia removal using activated carbons: effect of the surface chemistry in dry and moist conditions, Environ. Sci. Technol., 2011, 45, 10605-10610.

69 P. Nockemann, K. Binnemans, B. Thijs, T. N. Parac-Vogt, K. Merz, A. V. Mudring, P. C. Menon, R. N. Rajesh, G. Cordoyiannis, J. Thoen, J. Leys and C. Glorieux, Temperature-driven mixing-demixing behavior of binary mixtures of the ionic liquid choline, bis(trifluoromethylsulfonyl)imide and water, J. Phys. Chem. $B, 2009,113,1429-1437$. 